\title{
Modeling integration: co-teaching basic and clinical sciences medicine in the classroom
}

This article was published in the following Dove Press journal:

Advances in Medical Education and Practice

\author{
Joanne M Willey \\ Youn Seon Lim \\ Thomas Kwiatkowski \\ Department of Science Education, \\ Donald and Barbara Zucker School \\ of Medicine at Hofstra/Northwell, \\ Hempstead, NY, USA
}

Correspondence: Joanne M Willey Department of Science Education, Donald and Barbara Zucker School of Medicine at Hofstra/Northwell, 500 Hofstra Blvd, Hempstead, NY I I50 I, USA

Tel +I 5164637593

Fax + I 5164627414

Email joanne.m.willey@hofstra.edu
Purpose: Calls for revision in undergraduate medical education frequently cite the importance of integrating basic and clinical sciences and the use of active pedagogies. One under-appreciated approach to accomplishing both is interactive co-teaching, defined as two instructors with complementary expertise engaging students and each other instead of lecturing. This study sought to determine if interactive co-teaching helped students integrate and learn basic and clinical sciences, as well as to explore potential advantages and barriers to co-teaching.

Methods: The comparative success of solo- and co-teaching in a microbiology/infectious disease course was determined by surveying student perceptions at the end of the course and examination scores for questions based on either solo- or co-taught content. The advantages and barriers to co-teaching were explored by thematic analysis of student responses to openended survey questions.

Results: Results suggest that co-teaching supported content integration as a significant majority of students $(92 \%, \mathrm{n}=112)$ reported they understood the connection between basic and clinical sciences better when content was co-taught. In addition, a plurality of students indicated that co-teaching provided a better overall learning experience $(81 \%, n=99)$, was more engaging $(74 \%, n=90)$, and made it easier to apply content $(74 \%, n=90)$. These positive perceptions were reflected in better exam outcomes for materials covered in co-taught over solo-taught sessions. Conclusion: Results suggest students value co-teaching as a means to integrate basic and clinical sciences. However, interactive co-teaching pedagogies require careful planning and collaboration among faculty. Co-teaching requires the commitment of both faculty members to this pedagogy. Keywords: team teaching, microbiology, infectious disease, shared teaching, content integration, session integration

\section{Introduction}

Recommendations to integrate basic and clinical sciences throughout the undergraduate medical education (UME) experience have reached near-consensus. ${ }^{1,2}$ Empirical evidence supports the notion that content integration can improve diagnostic skills in early learners $^{3}$ and promote knowledge transfer. ${ }^{4,5}$ The drive for curricular reform also calls for the use of more active learning pedagogies, ${ }^{6,7}$ and some UME curricula have married these two recommendations to present integrated content through active learning instructional techniques. ${ }^{8}$ Active learning pedagogies are often rooted in the educational theory of constructivism, which at its core has four tenets: ${ }^{9}$ (1) knowledge cannot be passively transferred from teacher to student, rather students construct their own meaning from the information being taught; (2) a student's prior knowledge provides a scaffold upon 
which new learning is built; (3) social interaction facilitates learning; and (4) authentic tasks provide a platform for meaningful learning. ${ }^{10}$ These tenets intersect with adult learning theory, as an essential pillar of andragogy ${ }^{11}$ posits that adults learn best when content (in this case, basic science) can be applied immediately to a real-life situation (e.g., patient care).

Although there is a general agreement among medical educators that content integration and active learning pedagogies are beneficial, there is no consensus on how integration should be accomplished or what pedagogies are truly effective. ${ }^{6,12}$ Throughout these discussions, a commonly overlooked issue is the need for basic scientists and clinicians to work together to communicate the importance of both disciplines, model productive collaboration, ${ }^{13}$ and demonstrate the scientific underpinnings of medicine and its role in clinical reasoning. ${ }^{14}$ One very straightforward approach to meeting this goal is team-teaching. Among the three most commonly used models of team-teaching used in higher education, rotational team-teaching is most frequently adopted. ${ }^{15}$ Rotational team-teaching involves one or more individuals planning learning sessions delivered independently by different instructors; this describes the role of a course director and is not our focus. The other two models involve two or more instructors occupying the same teaching space during a single lecture or active learning session. In the participantobserver co-teaching model, multiple instructors (typically two) are present during class time, but take turns teaching in a lecture format. To accomplish both content integration and active learning, we have adopted the interactive co-teaching model, in which two or more instructors, each with distinct expertise, present complementary content together while engaging students in active problem solving and discussion. ${ }^{16}$

Interactive co-teaching is time-consuming, as it requires a great deal of collaborative planning by instructors, ${ }^{15,17}$ some of whom may feel it limits their autonomy. ${ }^{13}$ This may explain its limited use in higher education, where it was introduced in the 1960s. Within a decade, it fell into disfavor largely because challenges in orchestrating and executing such sessions were thought to exceed any perceived benefit. More recently, reports of co-teaching have reemerged at the undergraduate college level as instructors seek to integrate content in allied health professions ${ }^{13,18}$ and quantitative biology in a laboratory setting. ${ }^{19}$ Crow and Smith ${ }^{13}$ describe interactive co-teaching in a course that integrates wellness and social welfare. This qualitative study concludes that as compared to solo-teaching, students were more "actively engaged in synthesis and evaluation" of knowledge in co-teaching.

At the graduate level, reports of co-teaching are largely confined to business schools, although the Integrated
Graduate Program in Physical and Engineering Biology at Yale University has adopted a co-teaching approach to a primary literature-based seminar course. In this setting, 97\% of students agree that co-teaching including faculty with complementary expertise "is a successful method for enhancing communication skills across disciplines". ${ }^{20}$ Among MBA students, Higgins and Litzenberg ${ }^{15}$ assessed student perceptions of interactive co-teaching in an upper-division marketing course. Although acknowledging the challenges co-teaching can present, these authors find that more than $80 \%$ of respondents report that the co-taught course positively impacted their depth of content knowledge, interest in the content, perspective on teamwork, and overall learning.

Shared planning and teaching is described in the seminal paper of Harden ${ }^{21}$ as step six on the integration ladder, and co-teaching has been suggested as a means to integrate medical school curricular content. ${ }^{2,22}$ However, there is limited evidence of its use in lecture-based medical education. ${ }^{17} \mathrm{Co}-$ teaching in UME appears to be most commonly used in small groups of learners, where it is applied to problem-based and team-based learning sessions, ${ }^{23-25}$ or as a means to integrate basic science during third- and fourth-year clerkships. ${ }^{26}$ These studies report student perceptions, and in all cases, a majority of students agree that co-teaching enhanced their ability to apply basic science to clinically relevant problems.

We have found few studies describing interactive coteaching in UME that pair a basic scientist and a clinician in an active large group or lecture format. Further, we could find none in any discipline or at any level of instruction that report the impact of co-teaching on student outcomes. Here, we describe the use of interactive co-teaching using a guided inquiry instructional method, ${ }^{27}$ whereby students were provided real-world problems that triggered active discussion between students and two expert instructors. The purpose of our study was threefold: (1) to determine if students perceive interactive co-teaching as an effective pedagogy for the integration of basic and clinical sciences; (2) to assess the effect of co-teaching on student assessment outcomes; and (3) to use our experience combined with student feedback to provide lessons learned to others who might consider this pedagogy.

\section{Methods}

\section{Setting and participants}

This study took place in the fall of 2015 and 2016 within a required second-year undergraduate immunology/microbiology course called "Interacting with the Environment" (IE) at the Donald and Barbara Zucker School of Medicine at Hofstra/Northwell (Zucker SOM). In 2015, 98 students 
were enrolled; in 2016, there were 99 students. Each class had slightly more women than men (53\% and $52 \%$ women in 2015 and 2016, respectively). The average age of the students in both classes was 24 years $(\mathrm{SD}=1.9$ in $2015, \mathrm{SD}=2.6$ in 2016). Proportion and mean difference tests were conducted for demographic characteristics in the two classes; no differences were observed in gender, undergraduate and graduate degrees, age, and duration between undergraduate and medical school. The goals, learning objectives, and faculty were the same for all lectures, which we more accurately refer to as large-group sessions, for both years of the study. All student responses to surveys were therefore combined into a large sample consisting of 197 students, whereas outcomes data were calculated separately for each class because there were no common items in the examinations given in 2015 and 2016. The institutional review board of Hofstra University determined this study to be exempt from review.

\section{Course context}

The IE course was first taught in 2012, when our inaugural class reached its second year. Based on student and faculty feedback, the course was extensively revised in 2013. Since that time, the course consistently received overall positive student and faculty evaluations; however, we continue to refine content delivery. As part of this effort, co-teaching was first used in 2014, the year prior to this study.

The microbiology/infectious disease portion of the IE course consisted of seven weeks of instruction followed by one week of examinations. Each year included six hours per week of case/problem-based learning in a small group format that was student-driven (facilitators guided process, not content), and four to six hours per week of interactive large-group sessions that covered the mechanisms of health, disease, and intervention. All solo- and co-taught largegroup sessions involved the entire class and were 50 or 100 minutes in duration. Zucker SOM places a strong emphasis on learner engagement, and all students were expected to attend all sessions well prepared and ready to participate. To that end, all afternoons were available for self-directed learning with the exception of one afternoon per week, when students were paired with clinical preceptors in a community pediatrics practice. Additional learning experiences (not part of this study) included the following: a three-hour session in which small teams of students explored cases in a clinical diagnostics laboratory facilitated by either a microbiologist or an infectious disease physician and four, two-hour, case-based small-group sessions with a quizzing-based format. These sessions were student-driven, and facilitated by clinicians and microbiologists. All learning sessions described above were mandatory.

\section{Solo- and co-teaching pedagogy}

As a matter of policy, all instructors received faculty development that focused on developing and facilitating questions to promote student engagement through Socratic questioning $^{28}$ and other techniques. Students were introduced to the interactive nature of Zucker SOM large-group sessions very early in the first year of medical school and therefore expected facilitated discussion in all such sessions. Although large-group sessions occurred in a lecture hall, microphones built into desktops served to amplify students' questions and comments. A variety of techniques were used to ensure broad student participation. Examples include "pair and share", breakout groups of three to five students, and the use of audience response or "clicker" systems (solo-teaching only). Students were encouraged to ask questions, and instructors were practiced at using student inquiries as "teachable moments" to engage the entire class. The volume of preparation, in the form of reading, short videos, and podcasts, was similar for solo- and co-taught sessions.

Instructors included four clinicians and two basic scientists. The distribution of solo- and co-teaching is presented in Table 1. A microbiologist led the majority of solo-taught sessions. The same microbiologist and a single clinician led the majority of co-taught sessions. All solo-taught sessions led by a scientist were organized around fundamental principles (e.g., bacterial metabolism), whereas solo-taught sessions led by a clinician were case-based and focused on a specific type of infectious disease category (e.g., neonatal infections). All solo-taught large-group sessions were interactive, based on the principles of Socratic questioning, ${ }^{28}$ although some scientist-led sessions also included hands-on activities.

Instructors developed solo-taught sessions independently. By contrast, all co-taught sessions were developed collaboratively by the presenting scientist and the clinician and followed a similar format. The clinician began with a brief case presentation, and students were asked what else they needed to know (e.g., travel history, specific labs) to develop a differential diagnosis confined to an infectious disease. This allowed students reflect on what they already knew, identify and discuss the gaps in their knowledge, and develop ideas about problem solving. As the students narrowed their differential diagnosis, the clinician guided the students through diagnostic decision-making steps. Using similar interactive pedagogical methods alongside the clinician, the microbiologist facilitated a discussion focusing on the microbiology of 
Table I Solo- and co-teaching faculty

\begin{tabular}{llllll}
\hline $\begin{array}{l}\text { Basic } \\
\text { scientists }\end{array}$ & $\begin{array}{l}\text { No. of solo- } \\
\text { taught sessions }\end{array}$ & Clinicians & $\begin{array}{l}\text { No. of solo-taught } \\
\text { sessions }\end{array}$ & $\begin{array}{l}\text { Co-teaching } \\
\text { faculty pairs }\end{array}$ & $\begin{array}{l}\text { No. of co-taught } \\
\text { sessions }\end{array}$ \\
\hline Prof A & 7 & Prof W & 0 & Profs A and W & 6 \\
Prof B & 2 & Prof $X$ & 2 & Profs A and Y & I \\
& & Prof $Y$ & 1 & & \\
\hline
\end{tabular}

Notes: Prof $A$ is a PhD microbiologist. Prof $B$ is a PhD immunologist. Prof $W$ is an emergency medicine physician. Profs $X, Y$, and $Z$ are infectious disease physicians.

the causative infectious agent and the rationale for specific microbiological tests. Students were then asked to hypothesize how best to treat the patient, and the faculty continued joint discussion of the physiological and microbiological rationale for interventions. Both the clinician and the scientist provided their perspective in responding to questions and helped steer the discussion to cover predetermined content. Thus, all sessions included both clinician-led and scientistled interactions with students, as well as clinician-scientist interactions and clinician-scientist-student discussion. Using this approach, both instructors facilitated the discussion of the clinical presentation, diagnosis, treatment, as well as microbiological principles of an infection disease.

\section{Assessment methodology}

In an effort to assess the impact of co-teaching, three different types of data were collected: (1) at the conclusion of each solo- and co-taught sessions, students were asked to evaluate the teaching performance of each instructor; (2) student perceptions regarding solo- as compared to co-teaching were surveyed at the conclusion of the IE course; and (3) assessment outcomes for test items derived from solo-taught sessions were compared to those from co-taught sessions. These three approaches are discussed below in more detail.

\section{Teaching evaluations}

To determine if students perceived the teaching performance differently among the individual instructors, teaching evaluations were distributed following the solo- and co-taught sessions. For co-taught sessions, students completed two separate teaching evaluations, one for each faculty member. This instrument consisted of seven questions anchored to a five-point Likert scale that queried the value of the required prework, instructor's verbal and nonverbal communication, organization, the use of thought-provoking questions to promote student learning, and the tone of the learning environment (Figure $\mathrm{S} 1$ ). The completion of teaching evaluations by students is a required element for successfully passing the administrative component of all Zucker SOM courses.

\section{Student perception of solo- as compared to co-teaching}

To assess student perceptions of co-teaching as compared to solo-teaching, participants were invited to voluntarily complete a brief survey regarding their attitudes toward these presentation types at the conclusion of the course (Figure S2). The response rates were 67\% $(\mathrm{n}=66)$ in 2015 and $57 \%(\mathrm{n}=56)$ in 2016 , with an overall survey response rate of $62 \%(n=122)$. Using items anchored to a five-point Likert scale, students were asked to rank their satisfaction with the overall learning environment, their understanding of content, and their perceived ability to retain and apply content. Analysis of student responses to both the teaching performance and solo-/co-teaching instruments was performed using nonparametric tests for mean comparison. Several open-ended questions were also included (Figure S2). Two researchers performed inductive thematic analysis; open coding of comments was conducted, and preliminary themes were reconciled to establish the final themes. ${ }^{29}$ Final content analysis was performed using QSR International's NVivo 11 software (QSR International, Doncaster, VIC, Australia).

\section{Student outcomes analysis}

The impact of solo- and co-teaching on student outcomes as assessed by final examinations held in 2015 and 2016 was also analyzed. All summative examinations at Zucker SOM are essay-based. Final essay exams consisted of 11 brief clinical scenarios, each with two to seven associated short-answer essay questions. Although the examinations were not identical in each year of the study, the same content was assessed. Each year's examination consisted of 38 questions. The learning session during which the content was delivered was determined for each question; a subset of questions judged to be unequivocally based on content delivered during either co- or solo-taught sessions were used for analysis. Questions were mapped using Bloom's taxonomy to one of three categories: foundational knowledge, application, or problem solving (synthesis). There were five first-order questions in the soloteaching category and six in the co-teaching, ten and eleven 
application questions in the solo- and co-teaching category, respectively, and three and two problem-solving questions in the solo- and co-teaching category, respectively. The course directors vetted all exam questions, ideal answers, and rubrics. Questions were worth between one and three points, and care was taken to specifically delineate what constituted full, partial, or zero credit. During the grading process, all student identities were anonymous. To eliminate inter-rater variability, one faculty member graded all responses to his/ her assigned questions.

In order to control for item difficulty, the one-parameter item response theory model was used for item calibration and assessment of student ability $(\theta)$. Item difficulties were first estimated using marginal maximum likelihood estimation. Then, each individual student's ability $(\theta)$ was estimated using the maximum a posteriori scoring method. Finally, the mean and sigma equating method was used to compare the two groups of questions. ${ }^{30}$ This statistical analysis is of higher validity than simply comparing the mean scores for the items from solo- vs. co-taught session, given that individual items may have differed in difficulty levels. All analyses were conducted using R statistical software, version 3.3.2 (R Foundation for Statistical Computing, Vienna, Austria) and MATLAB, version R2017a (The MathWorks, Inc., Natick, MA, USA).

\section{Results}

To determine if student perception of teaching performance might influence students' views on solo- and co-teaching, students completed teaching evaluations for all instructors involved in this study. No significant difference in teaching performance among instructors was found. Additionally, no statistically significant difference was found when teaching performance evaluations were categorized as solo- or cotaught (Table S1).

On the other hand, when asked to consider the type of instructor and pedagogy (solo-clinician, solo-basic scientist, or co-teaching by both), student perception was significantly different for sessions taught by a clinician, a scientist, or a scientist-clinician pair (Figure 1). This was verified by applying a Mann-Whitney-Wilcoxon test (solo- and co-teaching comparison) and Kruskal-Wallis test (scientist solo-, clinician solo-, and co-teaching comparison), which determined the mean rank difference between the instructional models (Table 2). When specifically asked to compare solo- and coteaching as pedagogies, a significant majority of students $(81 \%, n=99)$ agreed or strongly agreed that co-teaching improved their overall learning experience, engagement, ability to apply content, understanding of clinical science, and the connection between basic and clinical sciences (Figure 1). Only the ability to understand basic science was reported as being more effective when delivered by a single instructor, a basic scientist. Interestingly, there was no preference for solo- or co-teaching in terms of content retention.

In addition to the Likert-scale items, students were asked several open-ended questions that were analyzed for themes (Table 3). In response to the question "What do you like most about sessions led by a scientist-clinician pair?", the leading theme was the connection between basic and clinical sciences. For example, one student commented as follows:

Basic science and clinical application are fluid, not discrete. I very much enjoy the way basic science applies to clinical scenarios and I like the details and logistics provided by the clinician. It gives a truly holistic view of the patientdisease interaction.

An unexpected theme that emerged was the appreciation of being able to ask questions about a wider range of topics when two experts led a session. Additional themes and example comments that emerged when analyzing the responses to this question are shown in Table 3.

On the contrary, when asked what students liked least about co-taught sessions, the majority of responses noted that sessions could be disjointed or distracting, depending on the dynamics between instructors and session organization. This is exemplified by the following comment:

These sessions require a lot of coordination and clarity of roles between the pair in order to be effective. This was not always the case, creating a bit of distraction at times.

This was echoed when students were asked if they would like more co-taught sessions. Although not all students responded to this open-ended question, among those who did, most stated they would like more $(66 \%, n=29)$, or that the number of sessions was appropriate $(11 \%, n=5)$. About a quarter of respondents $(23 \%, n=10)$ indicated they would prefer fewer co-taught sessions. Interestingly, even among those who responded positively, this was often conditional, noting co-teaching "requires a good dynamic between the scientist and clinician" (Table 3).

Finally, we sought to determine if these student impressions were reflected in summative examinations for the course. Thus, estimates of student ability $(\theta)$ from co-taught and solo-taught session exams were compared (Figure 2). Student ability, $\theta$, ranges from -3.00 to +3.00 , with average ability equal to zero. The results of a paired-sample $t$-test 


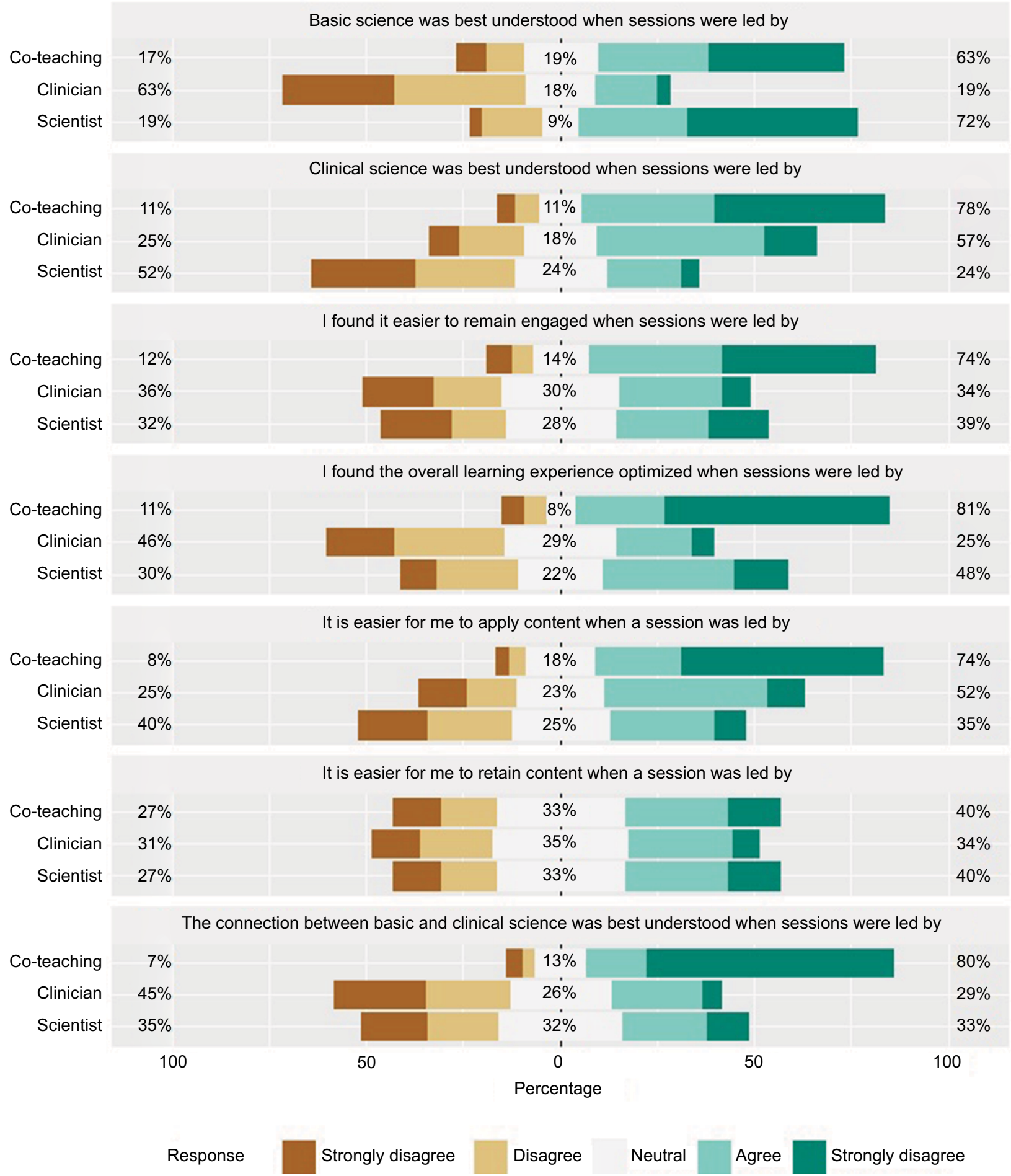

Figure I Comparison of attitudes toward solo- and co-teaching (response rate=62\%, $n=122$ ).

showed student ability was significantly above zero when tested for content covered in co-taught sessions $(\mathrm{M}=0.40$, $\mathrm{SD}=0.81, \mathrm{n}=98$ in 2015 and $\mathrm{M}=0.54, \mathrm{SD}=1.05, \mathrm{n}=99$ in 2016). This compares to student ability as determined by performance on questions derived from solo-taught sessions, which were at or close to zero $(\mathrm{M}=0.01, \mathrm{SD}=0.99, \mathrm{n}=98$ in 2015 and $\mathrm{M}=0.00, \mathrm{SD}=1.14, \mathrm{n}=99$ in 2016; $t(186.94)=3.14$, $p<0.01$ in 2015 and $t(195.1)=3.89, p<0.01$ in 2016). The estimates of $\theta$ of two sections were moderately related $(r(98)=0.32, p<0.05$ in 2015 and $r(99)=0.36, p<0.05$ in 2016). 
Table 2 Mean rank comparison of co-teaching and solo-teaching

\begin{tabular}{|c|c|c|c|c|c|}
\hline \multirow[t]{3}{*}{ Question } & \multicolumn{3}{|l|}{ Mean rank } & \multirow[t]{3}{*}{$\chi^{2}$} & \multirow[t]{3}{*}{ MW } \\
\hline & \multirow[t]{2}{*}{ Co-teaching } & \multicolumn{2}{|c|}{ Solo-teaching } & & \\
\hline & & Scientist & Clinician & & \\
\hline Overall learning experience $\mathrm{e}^{\mathrm{a}, \mathrm{b}, \mathrm{c}}$ & 248.28 & 166.33 & 125.18 & $92.11 *$ & $583.00 *$ \\
\hline Understanding basic science ${ }^{\mathrm{b}, \mathrm{c}}$ & 109.70 & 118.23 & 56.08 & $49.90 *$ & $1081.50 *$ \\
\hline Understanding clinical science $e^{\mathrm{a}, \mathrm{b}, \mathrm{c}}$ & 128.45 & 62.78 & 97.73 & $46.95^{*}$ & $680.00 *$ \\
\hline Understanding the connection ${ }^{\mathrm{a}, \mathrm{c}}$ & 257.95 & 150.18 & 131.42 & $109.31 *$ & $407.00 *$ \\
\hline Remaining engaged ${ }^{\mathrm{a}, \mathrm{c}}$ & 213.74 & |47.0| & 133.36 & $47.52 *$ & $643.50 *$ \\
\hline Retaining content $\mathrm{t}^{\mathrm{a}, \mathrm{c}}$ & 217.75 & 152.08 & 137.80 & $45.84^{*}$ & $645.00 *$ \\
\hline Applying content $\mathrm{t}^{\mathrm{a}, \mathrm{b}, \mathrm{c}}$ & 223.61 & 125.58 & 152.16 & $65.45 *$ & $509.50 *$ \\
\hline
\end{tabular}

Notes: $\chi^{2}$, Kruskal-Wallis test for three-group comparison. MW, Mann-Whitney U-test for co-teaching vs. solo-teaching comparison. ${ }^{*} p<0.01$. aPost hoc: scientist vs. coteaching comparison, $p<0.01$ in pair-wise Mann-Whitney $U$-test. ${ }^{b} P$ ost hoc: scientist vs. clinician comparison, $p<0.01$ in pair-wise Mann-Whitney $U$-test. ${ }^{c}$ Post hoc: clinician vs. co-teaching comparison, $p<0.01$ in pair-wise Mann-Whitney $U$-test.

Table 3 Themes from survey of students

What do you like most about sessions led by a scientist-clinician pair?

Context and holistic picture makes connections between basic sciences and clinical application more obvious

I liked how the clinical and the basic science aligned right there and then, and the connections were quite obvious.

These sessions really helped me to see the bigger picture of microbiology; it's more than just memorizing what bug and what drug, and these paired sessions gave a holistic picture! The thing I liked the most was how everything that was presented during these sessions was additive; Dr. $\mathrm{X}$ would say one thing, and Dr. A would add something else that built upon the last thing to give us multiple perspectives.'

Instructor team dynamics

I liked how each wasn't afraid to correct the other mid-lecture [...] I felt like I was always getting the right and relevant information.

I liked their camaraderie and ability to give details on each other's sessions.

More engaging and thought provoking

My favorite sessions in Interacting with the Environment (IE) Part 2 were the Approach To sessions that were led by a scientist-clinician pair because they were engaging, thought-provoking, and well-organized. I liked how the sessions were organized according to the patient's chief symptom and how the powerpoint slides were organized based on going through a differential diagnosis with clinical cases. I loved how slides about the basic science of microorganisms were included right after their related clinical slides because this really helped me to retain information about certain bugs and why it all mattered.

It is much more engaging to hear two expert voices that trade off rather than one voice that can get repetitive and cause students to lose interest. The constant dual interaction and switching off not only kept me more engaged, but I truly appreciated the assisting/playing off of one another's expertise to help explain disease processes from both lens[sic]. I think this combination was I. much more engaging; 2. much more thorough; 3. helped me retain more information.

Improves learning in terms of retention and/or provides a better understanding

The connections that exist between clinical and basic science help cement knowledge in my memory, and often these were pointed out because of the pairing.

Presence of both clinician and basic scientist is more efficient, can ask wider variety of questions.

The interaction between the presenters increased the levity of the session and it was nice to have experts in their fields be able to answer all questions.

\section{What do you like least about sessions led by a scientist-clinician pair?}

Presentation is disjointed or distracting

Bouncing back and forth between the scientist and clinician can be somewhat distracting to the flow of the lecture.

I guess it can be a bit of whiplash between the two lecturers, but it honestly did not matter that much in my learning.

It is sometimes difficult to focus on both clinical and basic science learning within one lecture. Sometimes it is nice to compartmentalize.

Lack of clarity of roles of each instructor

There sometimes seemed to be a lack of communication between the two - like one person wasn't always completely clear as to what the other would cover.

I think sometimes they were a little unorganized and seemed to veer off topic.

Amount of information makes prioritizing content difficult despite stated goals of session

There was an almost overwhelming amount of information when both the basic science and the clinical are taught together.

Sometimes it is overwhelming to learn about both the basic science of the microorganism and the clinical.

Note: 'Names of faculty changed for publication purposes. 


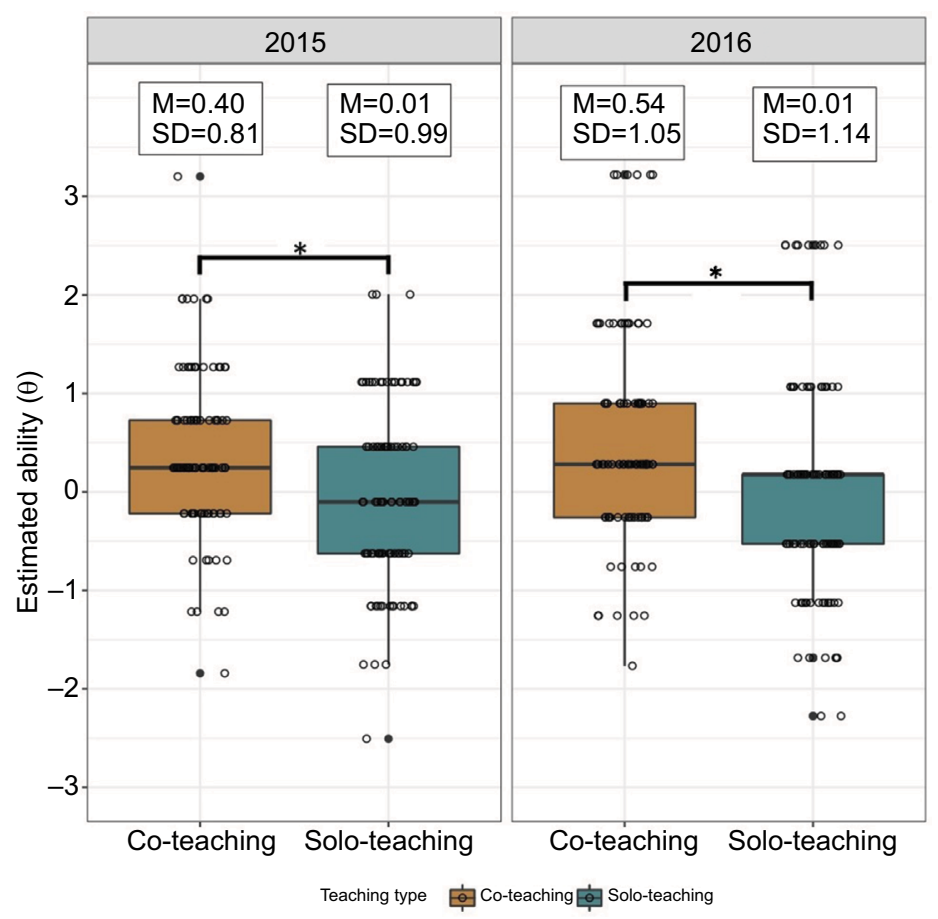

Figure 2 Comparison of equated and scaled exam score by teaching type.

Notes: *statistical significance, $p$-value $<0.05$.

\section{Discussion}

In developing the microbiology/infectious disease portion of the IE course, the course directors were challenged by Zucker SOM guiding curricular principles that stress (1) the integration of basic and clinical sciences and (2) the value of "conceptual knowledge in action, not memorizing facts". The latter aligns with recommendations of the Infectious Disease Society of America, but is contrary to how microbiology/ infectious disease is taught at many institutions. ${ }^{31}$ Although it is undeniable that microbiology/infectious disease requires memorization, we sought to shift the burden of rote memorization to "meaningful memorization", which contributes to deep learning. ${ }^{32}$ We began by constructing a course that started with three weeks of fundamental principles delivered in solo-taught basic science sessions. This was followed by four weeks of systems-based application of those principles through the use of co-taught sessions that embedded additional basic science in the context of clinical cases. This not only eliminated the so-called "bug parade", but our data also suggest that students better appreciated the connection between the basic and clinical sciences.

The goal of our interactive co-teaching approach was to employ guided inquiry so that students could construct and scaffold learning while solving authentic clinical questions. We believe the organizational structure of our co-teaching sessions satisfied the four essential elements of constructivism. ${ }^{9}$ Specifically, co-teaching faculty coached students to solve clinical problems while incorporating new content by starting with what they knew about a patient presenting with a specific condition (e.g., cough) and layering upon this new concepts (e.g., clinical presentation of atypical pneumonia). Basic science was woven into each case as a means of explaining "the why" of clinical presentation and providing a rationale for antibiotic selection. The social aspects of learning specific to co-teaching sessions included student-faculty interactions, interaction among students, and interaction between the two faculty presenters.

Survey results revealed that students were very positive about co-taught sessions overall. Interestingly, although they considered co-teaching to be more effective in helping them understand clinical science and the connection between clinical and basic sciences, a plurality of students either agreed or strongly agreed that they understood basic science best when solo-taught by a scientist. We postulate at least two reasons for this: first, although there were nine basic science sessions solo-taught by scientists with some clinical correlates, no strictly clinical sessions were held in this course. Therefore, students might feel just as strongly about solo-clinician-led sessions if the content were exclusively clinical. We also suspect that this preference may, in part, 
reflect student perception that basic science is more difficult and/or less familiar than clinical science. Reasons for this reported difference need further exploration.

Another important finding was the degree to which students agreed that co-taught sessions were more engaging than solo-taught sessions (Figure 1). This is particularly interesting because both solo- and co-taught sessions used Socratic questioning techniques designed to engage students (i.e., targeted questioning, follow-up questioning, and connection questions). ${ }^{6,28}$ This suggests student engagement had more to do with the integration of content and the social context of learning, rather than the use of Socratic questioning per se. Our co-teaching approach used carefully constructed model cases for student decision-making that required students to analyze clinical data and practice their reasoning skills, which was often done in impromptu small groups. As coteachers, we also modeled interactions between a clinician and a scientist when evaluating a patient's presentation and making clinical decisions, for example, in explaining the progression of a particular sign or symptom or the selection of a specific antibiotic, respectively. Student-centered active learning has become a goal for medical educators and a requirement of the Liaison Committee on Medical Education. ${ }^{6}$ In response, many institutions have adopted the flipped classroom model, ${ }^{33-35}$ some with mixed success. ${ }^{36}$ Our results suggest that co-teaching may be another effective means to engage students in active learning.

\section{Lessons learned}

As one student stated, interactive co-teaching "seems like such an obvious thing to do" in an integrated curriculum, yet we could find scant evidence of its adoption in the UME literature. Our results suggest this is a valid and potentially valuable pedagogy to advance UME content integration as well as student learning. However, students accurately perceive that organization and collaboration between co-teachers is requisite for successful execution. In this regard, many of our students' comments regarding the nature of interaction between the two co-teachers echo those reported by Crow and $\mathrm{Smith}^{13}$ in teaching allied health students. Our experience in developing and delivering interactive co-taught sessions provides the opportunity to share lessons we learned about this pedagogy, which we present in the following sections.

\section{Collaboration}

A basic scientist and a clinician must share the same vision for the session and work productively together to accomplish mutually agreeable goals and learning objectives. As Tra and
Evans ${ }^{19}$ point out, co-teachers need to develop and maintain good communication, strive to understand the other's point of view, and respect each other's expertise, which can lead to new insights for both the faculty and students.

\section{Time}

Preparation of co-taught sessions requires a significant investment in time that exceeds that needed for solo-taught sessions. As one student noted, more co-taught sessions are valuable "only if practiced beforehand".

\section{Willingness to focus content}

Both the clinician and scientist must realize that co-teaching in UME requires a level of focus that may be absent when solo-teaching. Both instructors must be cognizant of the specific learning objectives and avoid inserting tangential information.

\section{Sharing the stage}

Co-teaching is humbling; the basic scientist and clinician must be able to respect each other's time in front of students and accept the limits of their own expertise.

\section{Reflection and revision}

Like most pedagogical endeavors, each time a session is co-taught it provides an opportunity for improvement. Student evaluations as well as candid discussion between co-instructors should be used to modify the session if it is to be presented again.

\section{Limitations}

Our findings are limited in that they report student perception and outcomes of two final exams from a single course at one institution. Because only one course was investigated, the number of instructors was limited. In addition, co-teaching microbiology/infectious disease may offer a different set of challenges and opportunities for interactive co-teaching when compared to other disciplines. The latter limitation will be addressed at Zucker SOM as we introduce co-teaching to other courses.

\section{Conclusion}

Like many other medical schools, Zucker SOM is committed to an integrated curriculum. Here, we describe one strategy that can contribute to reaching this challenging goal at the session level. Our results suggest that the delivery of basic and clinical sciences in the same session by two content experts addresses two important goals of integration: increased 
comprehension and application of content. In addition to content integration, we found that interactive co-teaching can enrich the learning environment by engaging students in the elements of knowledge construction through dialogue, disagreement, and consideration of alternative perspectives. Indeed, when instructors converse and listen to each other and students, they become model learners ${ }^{37}$ in a way that is impossible for the solo-teacher. Finally, our students report that it is easier to apply co-taught content, thereby addressing the tenet first espoused by Knowles ${ }^{11}$ that adults learn best when the relevance of information is reinforced by its immediate application. Given the call for curricular reform in terms of content integration and more active pedagogy, we encourage more institutions to experiment with co-teaching and we invite discussion regarding their experiences.

\section{Acknowledgments}

The authors would like to thank Dr Elisabeth Schlegel and Dr Judith Brenner for helpful discussions and critical reading of this manuscript.

\section{Disclosure}

The authors report no conflict of interest in this work. The authors alone are responsible for the content and writing of the article.

\section{References}

1. Irby DM, Cook M, O’Brien BC. Calls for reform of medical education by the Carnegie Foundation for the Advancement of Teaching: 1910 and 2010. Acad Med. 2010;85(2):220-227.

2. Goldman E, Schroth WS. Perspective: deconstructing integration: a framework for the rational application of integration as a guiding curricular strategy. Acad Med. 2012;87(6):729-734.

3. Woods NN, Brooks LR, Norman GR. It all make sense: biomedical knowledge, causal connections and memory in the novice diagnostician. Adv Health Sci Ed Theory Pract. 2007;12(4):405-415.

4. Kulasegaram KM, Chaudhary Z, Woods N, Dore K, Neville A, Norman G. Contexts, concepts and cognition: principles for the transfer of basic science knowledge. Med Educ. 2017;51(2):184-195.

5. Cheung JJH, Kulasegaram KM, Woods NN, Moulton C, Ringsted CV, Brydges R. Knowing how and knowing why: testing the effect of instruction designed for cognitive integration on procedural skills transfer. Adv Health Sci Educ Theory Pract. 2018;23(1):61-74.

6. Graffam B. Active learning in medical education: strategies for beginning implementation. Med Teach. 2007;29(1):38-42.

7. Schwartzstein RM, Roberts DH. Saying goodbye to lectures in medical school - paradigm shift or passing fad. $N$ Engl $J$ Med. 2017;377(7):605-607.

8. Gülpinar MA, Yeğen BC. Interactive lecturing for meaningful learning in large groups. Med Teach. 2005;27(7):590-594.

9. Prince MJ, Felder RM. Inductive teaching and learning methods: definitions, comparisons, and research bases. J Eng Educ. 2006;95(2): 123-138.

10. Cooperstein SE, Kocevar-Weidinger E. Beyond active learning: a constructivist approach to learning. Ref Serv Rev. 2010;32(2):141-148.
11. Knowles MS. Self-Directed Learning: A Guide for Learners and Teachers. Chicago, IL: Follett Publishing Company; 1975.

12. Bandiera G, Boucher A, Neville A, Kuper A, Hodges B. Integration and timing of basic and clinical sciences education. Med Teach. 2013;35(5):381-387.

13. Crow J, Smith L. Using co-teaching as a means of facilitating interprofessinal collaboration in health and social care. J Interprof Care. 2004;17(1):45-55.

14. Hopkins R, Pratt D, Bowen JL, Regehr G. Integrating basic science without integrating basic scientists: reconsidering the place of individual teachers in curriculum reform. Acad Med. 2015;90(2):149-153.

15. Higgins LM, Litzenberg KK. Transferring experience through team teaching: the chance of a lifetime. Coll Teach. 2015;63(3): $105-111$.

16. Helms MM, Alvis JM, Willis M. Planning and implementing shared teaching: an MBA team-teaching case study. J Educ Bus. 2005;81(1):29-34.

17. Lee MW, Soborowicz MB. Evaluation of team-teaching as a means of integrating microbiology and pharmacology. Med Sci Ed. 2015;25(4):497-502.

18. Scott PJ, Altenburger PA, Kean J. A collaborative teaching strategy for enhancing learning of evidence-based clinical decision-making. JAllied Health. 2011;40(3):120-127.

19. Tra Y, Evans IM. Enhancing interdisciplinary mathematics and biology education: a microarray data analysis course bridging these disciplines. Life Sci Ed. 2010;9(Fall):217-226.

20. Nobel DB, Mochrie SGJ, O'Hern CS, Pollard TD, Regan L. Promoting convergence: the integrated graduate program in physical and engineering biology at Yale University, a new model for graduate education. Biochem Mol Biol Ed. 2016;44(6):537550.

21. Harden RM. The integration ladder: a tool for curriculum planning and evaluation. Med Ed. 2000;34(7):551-557.

22. Kulasegaram KM, Martimianakis MA, Mylopoulos M, Whitehead CR, Woods NN. Cognition before curriculum: rethinking the integration of basic science and clinical learning. Acad Med. 2013;88(10): $1578-1585$.

23. Stevenson FT, Bowe CM, Gandour-Edwards R, Kumari VG. Paired basic science and clinical problem-based learning faculty teaching side by side: do students evaluate them differently? Med Ed. 2005;39(1):194-201.

24. Kolluru S, Roesch DM, de la Fuente AA. A multi-instructor, team-based, active-learning exercise to integrate basic and clinical science content. Am J Pharm Ed. 2012;76(2):1-7.

25. Sakles JC, Maldonado RJ, Kumari VG. Integration of basic sciences and clinical medicine in a clerkship: a pilot study. Med Sci Ed. 2016;16(1):4-9.

26. Wilkens KM, Moore D, Rohrbaugh RM, Briscoe GW. Integration of basic and clinical science in the psychiatry clerkship. Acad Psychiatry. 2017;41(3):369-372.

27. Hmelo-Silver CE, Duncan RG, Chinn CA. Scaffolding and achievement in problem-based and inquiry learning: a response to Kirschner, Sweller, and Clark (2006). Educ Psychol. 2007;42(2):99-107.

28. Elkowitz DE. Socratic questioning to engage learners. In: Fornari A, Poznanski A, editors. How to Guide for Active Learning. Huntington, WV: International Association of Medical Science Educators; 2015.

29. Braun V, Clarke V. Using thematic analysis in psychology. Qual Res Psychol. 2006;3(2):77-101.

30. Hambleton RK, Swaminathan H, Rogers HJ. Fundamentals of IEM Response Theory. Newbury Park, CA: Sage; 1991.

31. Southwick F, Katona P, Kaffman C, et al. ISDA guidelines for improving the teaching of preclinical medical microbiology and infectious disease. Acad Med. 2010;85(1):19-22.

32. Hattie JAC, Donoghue GM. Learning strategies: a synthesis and conceptual model. NPJ Sci Learn. 2016;1:16013.

33. Sharma N, Lau CS, Doherty I, Harbutt D. How we flipped the medical classroom. Med Teach. 2015;37(4):327-330. 
34. McLaughlin JE, Roth MT, Glatt DM, et al. The flipped classroom: a course redesign to foster learning and engagement in a health professions school. Acad Med. 2014;89(2):236-243.

35. Gostelow N, Barber J, Gishen F, Berlin A. Flipping social determinants on its head: medical student perspectives on the flipped classroom and simulated patients to teach social determinants of health. Med Teach. Epub 2018 Feb 19.
36. White C, Bradley E, Martindale J, et al. Why are medical students 'checking out' of active learning in a new curriculum? Med Ed. 2014;48(3):315-324.

37. Anderson R, Speck BW. "Oh what a difference a team makes": why teamteaching makes a difference. Teach Teacher Educ. 1998;14(7): 671-686. 


\section{Supplementary materials}

Questions I-7, anchors include: Disagree (I), Somewhat disagree (2), Neither agree nor disagree (3), Somewhat agree (4), Agree (5)

I. The presentation reflected the stated goal(s) of the session.

2. The presentation was a logical extension of the pre-work.

3. Instructor communicated material at a level that was appropriate for the learners.

4. Instructor used effective nonverbal communication (e.g., enthusiastic, used appropriate gestures, eye contact, mannerisms).

5. Instructor was well organized, delivering content in a logical progression (e.g., slides support appropriate pacing and transitions between subjects).

6. Instructor engaged learners through the use of thought-provoking questions.

7. The tone or atmosphere of the session enabled learners to comfortably identify and address their concerns and/or limitations.

Figure SI Faculty evaluation.

Questions I-15, anchors include: Disagree (1), Somewhat disagree (2), Neither agree nor disagree (3), Somewhat agree (4), Agree (5)

Over the course of Interacting with the Environment, you have experienced large group sessions taught by basic scientists, clinicians, and basic scientist/clinician pairs. Please reflect on these sessions to answer the following questions:

When learning about microorganisms and the diseases they cause...

I) I found the overall learning experience optimized when led by a scientist alone

2) I found the overall learning experience optimized when led by a clinician alone

3) I found the overall learning experience optimized when led by a scientist-clinician pair

4) The connection between basic and clinical science was best understood when sessions were led by a scientist alone

5) The connection between basic and clinical science was best understood when sessions were led by a clinician alone

6) The connection between basic and clinical science was best understood when sessions were led by a scientist-clinician pair

7) I found it easier to remain engaged when a session was led by a scientist alone

8) I found it easier to remain engaged when a session was led by a clinician alone

9) I found it easier to remain engaged when a session was led by a scientist-clinician pair

10) It is easier for me to retain content when a session was led by a scientist alone

II) It is easier for me to retain content when a session was led by a clinician alone

12) It is easier for me to retain content when a session was led by a scientist-clinician pair

13) It is easier for me to apply content when a session was led by a scientist alone

14) It is easier for me to apply content when a session was led by a clinician alone

15) It is easier for me to apply content when a session was led by a scientist-clinician pair

16) What do you like most about sessions led by a scientist-clinician pair? Why?

17) What do you like least about sessions led by a scientist-clinician pair? Why?

18) Do you think more sessions should be led by a scientist-clinician pair? Why or why not?

Figure S2 Shared teaching survey. 
Table SI Evaluation of teaching performance

\begin{tabular}{|c|c|c|c|c|c|c|c|c|}
\hline \multirow[t]{2}{*}{ Group } & \multirow[t]{2}{*}{ Instructor } & \multicolumn{7}{|c|}{ Mean rank of evaluation item } \\
\hline & & $\mathbf{I}$ & 2 & 3 & 4 & 5 & 6 & 7 \\
\hline \multirow[t]{5}{*}{ Solo } & Clinician X & 83.09 & 98.20 & 99.73 & 87.23 & 88.48 & 97.64 & 84.59 \\
\hline & Clinician Y & 91.21 & 79.39 & 83.04 & 92.79 & 95.07 & 92.29 & 98.05 \\
\hline & Clinician Z & 91.21 & 79.39 & 83.04 & 92.79 & 95.07 & 92.29 & 98.05 \\
\hline & Scientist A & 114.34 & 118.54 & 121.50 & 115.39 & 120.73 & 120.55 & 111.54 \\
\hline & Scientist B & 120.66 & 117.84 & 110.08 & 123.21 & 121.13 & 106.52 & 117.84 \\
\hline \multirow[t]{2}{*}{ Co } & Co-teacher A & 104.69 & 105.61 & 104.19 & 101.34 & 96.26 & 106.15 & 105.23 \\
\hline & Co-teacher W & 112.68 & 118.50 & 117.03 & 105.95 & 103.03 & 104.68 & 103.79 \\
\hline \multirow[t]{3}{*}{ MW } & Co vs. Solo & 4080.50 & 3871.50 & 3961.00 & 4393.00 & 4225.00 & 4283.50 & 4339.5 \\
\hline & Three groups & $11.50 * \mathrm{~b}$ & $14.63^{* b, c}$ & $10.08^{* b}$ & $10.53^{* b}$ & $9.96 * \mathrm{~b}$ & 4.61 & 5.70 \\
\hline & Overall & 12.50 & $17.69 * *$ & $|3.3| * *$ & 11.20 & 10.49 & 5.83 & 7.13 \\
\hline
\end{tabular}

Notes: MW, Mann-Whitney U-test for co-teaching vs. solo-teaching comparison. $\chi^{2}=$ Kruskal-Wallis test for overall comparisons. Post hoc Mann-Whitney U-test with Bonferroni correction was conducted revealing that no instructor-by-instructor comparisons were significantly different. ${ }^{*} p<0.05$. $* * p<0.05$. ${ }^{a} P o s t$ hoc: scientist vs. coteaching comparison, adjusted $p<0.05$ in pair-wise MW. ${ }^{b}$ Post hoc: scientist vs. clinician comparison, adjusted $p<0.05$ in pair-wise $M W$. ${ }^{c}$ Post hoc: clinician vs. co-teaching comparison, adjusted $p<0.05$ in pair-wise MW.

\section{Publish your work in this journal}

Advances in Medical Education and Practice is an international, peerreviewed, open access journal that aims to present and publish research on Medical Education covering medical, dental, nursing and allied health care professional education. The journal covers undergraduate education, postgraduate training and continuing medical education including emerging trends and innovative models linking education, research, and health care services. The manuscript management system is completely online and includes a very quick and fair peer-review system. Visit http://www.dovepress.com/testimonials.php to read real quotes from published authors.

Submit your manuscript here: http://www.dovepress.com/advances-in-medical-education-and-practice-journal 